\title{
IS DECENTRALIZATION REALLY WELFARE ENHANCING?: EMPIRICAL EVIDENCE FROM SURVEY DATA (1994-2011)
}

\author{
Paper accepted for publication at Kyklos \\ Marta Espasa \\ Alejandro Esteller-Moré \\ Toni Mora*
}

\begin{abstract}
Decentralization is believed to constitute the optimal institutional arrangement for public good provision. In contrast to centralization, it is thought to offer a better match between provision and individual preferences. We test this hypothesis by analyzing the Spanish decentralization process undergone since 1980s exploiting survey data. A higher degree of satisfaction is expressed when education and health provision is assigned to the intermediate tier of government rather than to central government. This, however, is not recorded for largest regions or for the case of the justice administration, where the responsibility assigned to (some) regions is of a merely administrative nature.
\end{abstract}

Keywords: public expenditure allocation, decentralization, preference matching JEL Codes: H40, H50, H72, H77

\footnotetext{
${ }^{*}$ Marta Espasa and Alejandro Esteller-Moré (corresponding author), Departament d'Economia, Universitat de Barcelona, and Institut d'Economia de Barcelona (IEB), Barcelona, Spain, Email: mespasa@ub.edu, aesteller@ub.edu; Toni Mora, Departament d'Economia i Organització d'Empreses, Universitat Internacional de Catalunya Barcelona, Spain, E-mail: tmora@uic.es. We would like to acknowledge funding from the Institut d'Estudis Autonòmics (Generalitat de Catalunya), and from projects 2014SGR420 (Espasa and Esteller-Moré) and 2014SGR1360 (Mora). We also acknowledge financial support from the Spanish Ministry of Economy and Competitiveness (ECO2012-37131, ECO2012-37873 and ECO2013-48217-C2-1-R, respectively). Finally, we thank Umberto Galmarini, an anonymous referee and the Editor for very useful comments and suggestions. The usual disclaimer applies.
} 


\section{INTRODUCTION}

Is fiscal decentralization welfare enhancing? According to the mainstream of the literature on fiscal federalism, the answer is yes. However, surprisingly very few studies have empirically tested this assumption ${ }^{1}$. The claim is that fiscal decentralization brings about gains in the allocative efficiency of public service provision (Tiebout, 1956; Oates, 1972) ${ }^{2}$. Thus, according to Oates' decentralization theorem, in the absence of economies of scale, sub-central government provision will be at least as efficient as that of central government, provided the latter is restricted to providing a uniform composition of public expenditure throughout the territory and differences in demand exist between jurisdictions. Similarly, the "voting-with-the-feet" argument developed by Tiebout rests on an analogy between private market provision and public provision, whereby physical mobility - for an infinite supply of local jurisdictions - should lead to citizens taking up residence in that jurisdiction where the composition of public expenditure perfectly matches their individual preferences.

Yet, these theories might be considered as being somewhat restrictive. For example, the traditional literature assumes a decision-making process based on a benevolent policymaker abstracting from political economy considerations; and, moreover, in some contexts, physical mobility is far from cost-free. In attempting to overcome these restrictions, the second-generation theory of fiscal federalism (Oates, 2005) frames the analysis within the context of political economy. In this case, even if there were no physical mobility, yardstick competition (Besley and Case, 1995), or simply a better representation of the decisive voter under representative democracy (Seabright, 1996; Besley and Coate, 2003), would mean that the allocation of public expenditure was superior to that under centralized decision-making ${ }^{3}$. All in all, fiscal decentralization

\footnotetext{
${ }^{1}$ Diaz-Serrano and Rodriguez-Pose $(2012,2015)$ rightly argue that many studies test for the impact of decentralization on poverty reduction, economic growth, inter-personal inequality, formation of social capital, and so on, but that they tend to miss the point, which is determining whether decentralization leads to a better public delivery of services and, as a consequence, to an enhanced level of social welfare.

${ }^{2}$ See Eppel and Nechyba (2004), section 4, for a complete review of this question.

${ }^{3}$ Interestingly, the process of decentralization could simultaneously imply an efficiency gain in those regions where provision is still centralized. This could be due to a process of vertical yardstick competition (Breton and Fraschini, 2003). We thank the Editor for pointing out this possibility.
} 
should improve political accountability and, with it, social welfare ${ }^{4}$.

The empirical literature, which is reviewed in detail in the next section, has adopted a range of different approaches when testing for the presence of welfare gains under decentralization and, in almost all instances, the empirical evidence is favorable to decentralized institutional arrangements. Some papers have focused on whether the outcomes of certain public policies (or indeed general subjective well-being) improve when provision is decentralized (Hoxby, 2000; Treisman, 2002; Cantarero and Pascual, 2008; Bjørnskov, Drehe and Fischer, 2008; Kyriacou and Roca-Sagalés, 2011; DíazSerrano and Rodríguez-Pose, 2012; Falch and Fischer, 2012; or Caldeira, Foucault, Rota-Graziosi, 2012 and 2015); others on whether decentralized public policies are more responsive to expenditure needs (Faguet, 2004; Esteller-Moré and Solé-Ollé, 2005; Borge, Brueckner and Rattsø, 2014); others have examined whether politicians have better knowledge about voter preferences in small jurisdictions (Dahlberg, Mörk and Ågren, 2005); while a final strand of the empirical literature has turned its attention to the question of whether public expenditure composition varies as a consequence of decentralization (González-Alegre, 2010; Arze del Granado, Martínez-Vazquez and McNab, 2012; and again, Borge, Brueckner and Rattsø, 2014). The approach followed by most of these papers is general enough to accommodate welfare gains due to greater levels of allocative efficiency and of productive efficiency. In contrast, Barankay and Lockwood (2007) and Balaguer-Coll, Prior and Tortosa-Ausina (2010) explicitly focus on productive efficiency. In this paper, we seek to estimate the welfare gains stemming from allocative efficiency.

Litvak, Ahmad and Bird (1998, p. vii) argue that 'decentralization is neither good nor bad for efficiency, equity or macroeconomic stability; but rather [...] its effects depend on institution-specific design'. In line with this reasoning, we test whether there are gains in efficiency as a consequence of decentralization, but also we seek to determine whether the very nature of decentralization is relevant at all. Specifically, we test whether a higher level of tax autonomy enhances efficiency due to greater freedom in

\footnotetext{
${ }^{4}$ Ultimately, as Wildasin (1995 p.2) points out, this means that "exit" (first-generation theories), "voice" (second-generation theories) or both are more easily attained under decentralization. See also the interesting reflections combining both approaches by Eichenberger (1994).
} 
the design of public policies and greater political accountability ${ }^{5}$.

We focus our study on the case of Spain and draw on available survey data. The decentralization process in Spain has been sufficiently rich over time and across its regions or state-level governments (the so-called "Comunidades Autónomas" (ACs)) to present enough variation to test our hypotheses. With some gaps ${ }^{6}$, our survey data cover the period 1994-2011, during which time we find cases of centralized and decentralized provision for the same service for a given year. The survey contains information from approximately 2,500 respondents per year, giving a total, after filtering, of a pool of around 20,000 observations. The great advantage of this sample is that, in contrast with cross-country data, we do not need to match individual data with macro data to account for (the degree of) decentralization. This means, on the one hand, that our dependent variable is based on individual responses regarding the degree of satisfaction with the public service provision of health, education and justice; while, on the other, we know the $\mathrm{AC}$ in which the respondent resides and whether the corresponding service is decentralized. The key point, here, is that for purposes of identification not all ACs assumed responsibility for the corresponding expenditure at the same time.

We obtain robust empirical evidence that points to the superiority of sub-central public service provision. Citizens show a greater level of satisfaction when the $\mathrm{AC}$ in which they reside is responsible for the provision of education and health, being greatest the positive impact of decentralization on health. However, in the case of justice, decentralization does not make a difference. In this latter case, note those ACs in charge of this service are mere administrators, so welfare gains - if any -would be due to productivity gains, and not to allocative efficiency gains. The estimated welfare gains in the first two services, though, depend on the population size of the region. For regions approximately with more than 1.8 inhabitants for education and with more than 2.8 million inhabitants for health, the gains are very imprecisely estimated such that no clear-cut conclusion - within our population sample - can be inferred. The estimated impact of the nature of decentralization, in particular, when this includes tax revenue

\footnotetext{
${ }^{5}$ See, for example, Brueckner (2009) or Peralta (2011).

${ }^{6} \mathrm{We}$ do not have any information on satisfaction about public good provision for the period 2001-04, as the question was not included in the survey.
} 
decentralization, on satisfaction is null.

The rest of the paper is organized as follows. In Section 2, we review the main theoretical and empirical literature on the welfare gains of fiscal decentralization. In Section 3, we describe the process of decentralization in Spain, since its dynamics over time and across its regions is very rich. In Section 4, we present our database and discuss our identification strategy. Results are presented in Section 5 and conclusions drawn in Section 6.

\section{LITERATURE REVIEW}

Decentralization might not be without its costs (Prud'homme, 1995) or, at least, a careful design of the political process should be implemented to guarantee its supposed welfare gains (see, for example, Weingast, 1995 \& 2009, for a description of the necessary conditions to ensure maximum welfare gains). Wasteful duplication of operating costs, or greater effectiveness of interest groups at the local level (Bardhan and Mookherjee, 2000; Bordignon, Colombo and Galmarini, 2008) are some of the potential costs of decentralization (see Rodríguez-Pose and Gill, 2005, for a recent detailed review of these costs). Despite this, in our empirical analysis, we focus on the supposed gains of decentralization associated with a better matching between public service delivery and individual preferences, i.e., allocative efficiency.

The superiority of sub-central governments in assessing individual demands for local public services (first-generation theories of fiscal federalism) and their greater incentives to infer these demands in the process of political competition (secondgeneration theories) are usually taken for granted. All in all, the outcome should be a better match between the demands of the representative citizen and public service provision in each region. This is the focus of our empirical paper. Below we review some of the papers mentioned in the Introduction, all of which (with the exception of Barankay and Lockwood, 2007) employ empirical methods to test for the presence of welfare gains attributable to allocative efficiency.

Taking advantage of a 1994 decentralization reform in Bolivia, Faguet (2004) tested, first, whether the composition of public investment changed with respect to the pre- 
1994 situation and, second, and more importantly, whether the new pattern was responsive to local needs. For the 1987-1996 period he found empirical evidence of a change in the investment pattern in education, water and sanitation, agriculture, transport, urban development and communication, industry and tourism and water management; he found no significant differences in health expenditure. In the case of education, for example, local investment tended to be higher in areas with higher rates of illiteracy, while investment in water and sanitation was higher in areas where people had no sewerage. Hence, decentralization resulted in a new pattern of public service provision, reflecting local expenditure needs and, thus, providing unequivocal indirect evidence of welfare gains due to increased allocative efficiency.

Borge, Brueckner and Rattsø's (2014) analysis is very similar to Faguet's (2004), since they tested whether decentralization leads to heterogeneity in the design of public policies, and again whether this reflects differences in local demands. However, rather than comparing centralization vs. decentralization, they compared the former with partial decentralization. Specifically, they took advantage of a 1986 reform in Norway, where local governments were given greater discretion to assign their funds to different public policies, that is, they still depended on grants (partial decentralization), but they were not constrained to spend according to the guidelines laid down by central government (centralization). Their empirical analysis covered the period 1980 to 1991, and focused on the following public services: childcare, primary and secondary education, and parks and cultural services. They found greater dispersion in the levels of local public provision between 1986-91 (partial decentralization) than between 1980-85 (centralization), a result in keeping with greater heterogeneity in local public demands.

Dahlberg, Mörk and Ågren (2005) used data from a 1996 survey conducted in 36 Swedish municipalities. In each municipality 60 individuals were randomly interviewed, with a response rate of between 77 and 97 per cent. Individuals/voters were asked about their preferences for locally provided services, in particular whether they were satisfied with current public expenditure or whether they would prefer higher or lower levels, while politicians were asked about their belief about their voters' preferences. The objective of their study was to determine whether politicians in small municipalities are relatively more aware of their constituents' preferences. In relatively small jurisdictions (under 4,200 inhabitants), politicians were clearly more aware of 
their voters' preferences, pointing to welfare gains from fiscal decentralization. In municipalities with more than 5,000 inhabitants, significant discrepancies were found between voters' preferences and what politicians actually think their voters want. Hence, according to this study, the benefits of decentralization stemming from allocative efficiency are dependent on the size of the jurisdiction.

Probably, the closest empirical paper to ours is Díaz-Serrano and Rodríguez-Pose (2015). They estimate to what extent citizens are satisfied with public provision of Education and Health across 31 European countries using the 2002, 2004, 2006 and 2008 waves of the European Social Survey (ESS). They relate this measure of satisfaction with a measure of decentralization distinguishing between fiscal and political decentralization. On the one hand, the former accounts for the importance of subcentral revenue and expenditure over total public expenditure. On the other hand, the latter makes a difference between self-rule (the authority is directly exercised by subcentral authorities) and shared-rule countries (subcentral authorities capacity to influence national politics). Fiscal decentralization has an unambiguously effect on satisfaction with respect to both public services, while the results regarding political decentralization are not so clear-cut.

In contrast with the previous analyses, Barankay and Lockwood (2007) focused their study on productive efficiency using Swiss data. They estimated a production function for education for the period 1982-2000, where the output variable was the percentage of 19-year-olds obtaining the maturité certificate allowing them to go on to university. Controlling for various inputs, including class size and the percentage of non-native speakers, they found that decentralization (measured as the percentage expenditure of the counties in each canton) increased the output achievement. Specifically, a 10 per cent increase in decentralization raised the share of 19-year-olds obtaining the maturité by $3.5 \%$. Therefore, according to this analysis, decentralization also adds welfare gains due to productive efficiency.

Again in contrast with the previous analyses, Treisman (2002) employed a crosscountry database (of up to 166 countries) and found no evidence in support of fiscal decentralization, given its negative impact on several measures of quality of government. The study measured decentralization in a variety of ways: for example, to 
account for local governments' supposedly superior knowledge of individual preferences, Treisman constructed a dummy variable equal to one if the country's constitution assigned at least one policy area exclusively to sub-national governments; to account for local electoral accountability he constructed a variable to account for the proportion of sub-national tiers of government with elected executives. Quality of government was measured via perceived corruption, as well as by means of various outputs or outcomes of government provision. For example, in the case of public health, he used the percentage of infants under 12 months that had been inoculated for diphtheria, tetanus and pertussis; for (basic) education, the rate of youth illiteracy; and for transportation infrastructure, the number of kilometers of paved road per resident.

Thus, all the above studies - with the exception of Treisman (2002) - find a positive effect of decentralization. In contrast to some of those analyses, the study reported here focuses on specific areas of expenditure, namely, education, health and justice, and examines individual levels of satisfaction for each. Our measure of decentralization takes advantage of Spain's dynamic process of devolution (see following section). Thus, decentralization, as in Faguet (2002), is a dummy equal to one if the corresponding expenditure competence has been decentralized. Our analysis also seeks to test for the impact of decentralization according to the nature of that process, given that the decentralization of expenditure and revenue responsibilities has not followed the same path over time. The ACs also vary considerably in terms of population size, so we are able to determine whether welfare gains - if any - are dependent on population. All in all, the peculiarities of the Spanish case ${ }^{7}$ should enrich previous analyses.

\section{THE PROCESS OF DECENTRALIZATION IN SPAIN}

Spain constitutes an interesting case study, having experienced an intense process of decentralization following the restoration of democracy in the late seventies. The

\footnotetext{
${ }^{7}$ An interesting study in this regard is Goodspeed (1994). This paper investigates the equity and efficiency consequences of the sub-central financial system in Spain in the late 1980s (characterized by a relatively low degree of tax autonomy) relative to a system based on decentralized revenue sources. Employing a theoretical model (unlike the empirical analyses reported in the studies reviewed above), Goodspeed finds efficiency losses of between 9 and more than $20 \%$ of revenue, depending on assumptions regarding the price and income elasticities of demand for public services.
} 
adoption of the Spanish Constitution in 1978 heralded the beginning of democracy, and the division of the State territory into ACs and municipalities. There are thus three levels of government: central, regional and local. The regional level, which did not exist before 1978 and comprises seventeen ACs, was created in recognition of the right to autonomy of the regions and nationalities in Spain ${ }^{8}$.

The ACs were gradually established between 1979 and 1983, and the central government began to transfer responsibilities and services to them. The origin of expenditure decentralization in Spain can be described as a political process in response to the wishes of having more self-government by the Basque Country and Catalonia, and to a lesser extent, by Galicia. Given this, in order to avoid a territorial conflict, decentralization spilt over the rest of regions but following a non-uniform evolution, as we will discuss below. Figure 1 shows the evolution in the relative importance of the Spanish public sector at different layers of government for the period 1970-2011. As can be seen, decentralization started in 1980 and has intensified thereafter: central government spending in 1980 accounted for $89.5 \%$ of the whole, while in 2011 it had fallen to $53.5 \%$. Regional government spending increased from $0 \%$ to $34.3 \%$, but the weight of local government spending did not increase. Health and education expenditure are the main items of regional expenditure; accounting for approximately $33 \%$ and $24 \%$ of total non-financial regional spending, respectively. While there has been a considerable degree of decentralization in public spending, there has been significantly less on the tax revenue side, although since the late 1990s there has been an increase in tax autonomy (see Durán and Esteller-Moré, 2005).

\section{[FIGURE 1]}

The Spanish Constitution (SC), the Statutes of Autonomy of each AC and the Local Government Act regulate the distribution of power by levels of government. The ACs assumed expenditure competences in an asymmetric fashion. Thus, depending on the specific route taken to autonomy, a distinction needs to be drawn between three types of AC: those created under article 143 of the SC, those created under article 151 of the SC,

\footnotetext{
${ }^{8}$ See, for example, Solé-Vilanova (1989).
} 
and the so-called "foral" communities". The route taken by the former grants access only to common responsibilities, and temporarily excludes two basic functions, i.e. health and education, while the other two types of AC assumed these responsibilities from the outset. However, responsibilities in education were gradually transferred to the remaining ACs under article 143 between 1995 and 1999, while responsibilities for health provision were transferred to all those ACs in 2002. In the case of the other two groups (the so-called "common regime"), foral ACs have (almost) complete tax autonomy. Table 1 shows the main differences between the different types of ACs.

\section{[TABLE 1]}

Table 2 shows the considerable variation in the timing of decentralization. For example, in the case of education, the Basque Country and Catalonia were the first ACs to assume this responsibility in 1981, while it took almost 20 years for a large group of ACs (Asturias, Castile-León, Castile-La Mancha, Extremadura, Community of Madrid and Region of Murcia) to take on this responsibility ${ }^{10}$. Catalonia was also the first AC to assume responsibility for the provision of health ${ }^{11}$. The decentralization of justice has followed a quite different path. In this case, decentralization refers to the "administration of the (Administration) of Justice"; that is, for example, there is only

\footnotetext{
9 "Foral" refers to Navarre and to the Basque Country (in particular, within the Basque Country, to the so-called "Diputaciones Forales", Álava, Guipúzcoa and Vizcaya), whose "historical rights" were explicitly recognized in the 1978 SC.

${ }^{10}$ With the restoration of democracy, Education was a political priority both for Catalonia and for the Basque Country to protect their own language and recover the ideals behind the short period of time of the II Republic (1931-36). That is why, they were the first ACs in assuming this responsibility. Soon after that, Galicia (1983) and Valencia (1984), which also have linguistic singularities to preserve, did the same, while Andalucía did it in 1983. The rest of ACs assumed this responsibility between 1999 and 2000, when the central government, in accordance with the article 143 of the Constitution, decided to transfer it to all the rest of ACs without carrying out, though, any previous economic analysis about the convenience of this expenditure decentralization.

${ }^{11}$ Having been Catalonia, as in Education, the first $\mathrm{AC}$ to assume the responsibility for the provision of Health, the rest of ACs of the article 151 were transferred this responsibility throughout the eighties and even the nineties. The revision of the financing model of the ACs in 2001 , which entered into force in 2002, supposed the generalization of the decentralization of this responsibility. In this regard, after a hard process of negotiation, the rest of ACs assumed it. In fact, the central government conditioned the implementation of the new financing system to the acceptance by these ACs of this expenditure responsibility. As in Education, the decision was not taken on the basis of an economic analysis.
} 
one General Council of the Judiciary (Consejo General del Poder Judicial), which oversees all Spanish judges. Moreover, entrance to the judiciary is via state examination. Hence, all the rules and guidelines governing the Administration of justice are fully centralized, although administrative matters relating to justice might be decentralized. Therefore, while we do not expect to detect any differences between the ACs in terms of the provision of justice, we might see differences in the production of the service. Indeed, it is unlikely that this latter dimension will have some impact on assessments of the service, as Esteller-Moré (2013) reports in another context. In all circumstances, it should provide indirect evidence of the potential importance of productive efficiency gains due to decentralization.

\section{[TABLE 2]}

The growth of the regional system and subsequent process of devolution have given rise to significant differences between regions in terms of the services transferred. These differences can be detected in their respective results, in the resources allocated to the services in each region, and in the organization of production. Medical outcomes differ markedly between the $\mathrm{ACs}^{12}$, for example, the infant mortality rate (number of deaths of infants under one year old per 1,000 live births) ranges from 1.78 in Navarre to 4.80 in Murcia. Other differences are found in the number of medical staff (doctors, specialists and nurses) per inhabitant, in the level of capital endowment (hospital beds, day hospital posts and operating rooms) per inhabitant, as well as in the provision of technology (nuclear magnetic resonance apparatus, radiation therapy, mammography, etc.). Thus, decentralization has led to a differentiated health service provision between Spain's regions. The same is true of education. Again, not only are there differences in academic results ${ }^{13}$, but there are also differences in inputs, including total education spending, the size of classes, and the number of pupils per teacher ${ }^{14}$. Some ACs provide free textbooks (Castile-La Mancha and Extremadura, among others) and specific

\footnotetext{
${ }^{12}$ See the Annual Reports of the National Health System, produced by the Observatory of the National Health System, Ministry of Health.

13 See, for example, a brief review of the PISA result by AC at http://www.mecd.gob.es/dctm/inee/internacional/pisa2012/boletin21 pisa2012.pdf?documentId= $\underline{0901 \mathrm{e} 72 \mathrm{~b} 8178650 \mathrm{~b}}$

${ }^{14}$ See Mora, Escardíbul and Espasa (2010).
} 
programs to support children's education and grants ${ }^{15}$.

\section{EMPIRICAL ANALYSIS}

\section{Data}

As we have seen in the previous section, over the last thirty years Spain has undergone a process of expenditure decentralization, which has not however been homogeneous across its ACs. Here, we specifically seek to exploit this time and cross-sectional variation to determine whether satisfaction with respect to public expenditure allocation has increased as a consequence of decentralization.

Our dependent variable is based on an annual survey carried out by a public research center, the Centro de Investigaciones Sociológicas (CIS). This is a repeated crosssection survey, based on a nationally representative sample of individuals, which focuses on subjective perceptions of the tax system and publicly provided goods and services in Spain. We use the 1994-2011 waves. Specifically, our dependent variable ranges from 1 (not at all satisfied with public provision) to 4 (the highest level of satisfaction $)^{16}$. Given the nature of the question, respondents' satisfaction might be due to a combination of allocative efficiency and productive efficiency, which we will try to disentangle. Moreover, given that we use a subjective measure of efficiency, there might be some individual biases. For example, if individuals are not users of a particular service, their responses might be arbitrary, or if they hold strong feelings per se about the decentralization process (e.g., given their nationalistic sentiments), they might tend to provide a systematically positive assessment of decentralized services. In the empirical analysis, we tackle these potential sources of bias.

\footnotetext{
${ }^{15}$ See Calero and Escardíbul (2005).

${ }^{16}$ The original survey question reads as follows in Spanish: “Diría Ud. que los siguientes servicios públicos funcionan muy satisfactoriamente, bastante, poco o nada satisfactoriamente"?, that is: "Would you say the functioning of the following public services is very, quite, a little or not at all satisfactory?" The list of public services may change from year to year, although education, health, and justice are always on the list. Unfortunately, though, as mentioned, this question was not included for the 2001-2004 waves.
} 
In Table 3, we show the main descriptive statistics. For our period of analysis, the total number of observations is 32,287 . However, the final number for each public service is smaller, as responses where the respondent refuses to answer or does not know how to respond were disregarded. The mean value of our endogenous variable - level of satisfaction - is 2.5 and 2.4 for education and health, respectively, while satisfaction for the provision of justice is lower at just below 2. In Figure 2, we show how levels of satisfaction vary according to whether provision is decentralized or centralized. As can be seen, justice receives the worst assessment, with around $40 \%$ of respondents claiming not to be at all satisfied. Such extreme assessments are not found for the other two services. Yet, the graphical comparison of centralization vs. decentralization does not allow us to draw any clear-cut conclusions. In the case of education and health, the distribution at the tails hardly changes, but as we know from Table 3, under decentralization average satisfaction is lower and higher for these services, respectively. A multivariate analysis should help us in ascertaining whether decentralization has had any impact on the level of satisfaction.

\section{[TABLE 3]}

[FIGURE 2]

\section{Empirical Framework}

For a given public service, we propose estimating a difference-in-difference model:

$$
S_{i j t}=x_{i j t}^{\prime} \beta_{1}+a c_{j t}^{\prime} \beta_{2}+\beta_{3} D_{j t}+e_{i j t}
$$

All the variables are expressed in levels, where $S_{i j t}$, satisfaction with public provision our endogenous variable -, is a qualitative variable for individual $i$ in $\mathrm{AC} j$ at time $t$, which ranges from 1 to 4 (see section 4.1), $x_{j i t}^{\prime}$ is a vector of individual characteristics (sex, age, civil status, years of education, and a vector of employment characteristics ${ }^{17}$

\footnotetext{
${ }^{17}$ The years of education and the vector of employment characteristics (including whether the respondent is self-employed or an employee, unemployed or retired) should proxy the respondent's level of income, which is not available from the survey.
} 
including occupation ${ }^{18}$, industry of employment ${ }^{19}$ and labor status) and $\beta_{1}$ is the corresponding vector of coefficients to be estimated, $a c_{j t}$ is a vector of characteristics of AC $j$ (in which the respondent resides) at time $t$ (population, GDP pc., percentage of immigrants, current public expenditure pc, and share of young people and old people to account for expenditure needs of education and health, respectively), $\beta_{2}$ is the corresponding vector of coefficients to be estimated, $D_{j t}$ is a binary indicator which equals 1 if the responsibility for providing the corresponding service is decentralized, $\beta_{3}$ - our key estimate - is the impact of decentralization on individual satisfaction with public provision, and $e_{i j t}$ is an error term with standard properties. We expect $\beta_{3} \geq 0^{20}$.

In the case of the dependent variable, we assume interpersonal comparability of satisfaction, i.e., individuals share a common understanding of what satisfaction means. The accumulated empirical evidence suggests that this is a sensible assumption, which is sustained by the ability, for example, of individuals to predict the satisfaction felt by other individuals from photographic evidence, and by the clear relationship between reported satisfaction and facial expression, such as smiling (for a discussion, see Clark, Frijters and Shields, 2008). Interpersonal comparability can be assumed at the ordinal or cardinal level. In the first case, utility is assumed to be ordinal so that, for instance, individuals reporting a 4 are more satisfied than those reporting a 2, but not necessarily twice as much. If we assume interpersonal comparability at the cardinal level the distances between the answers provide information, which means that someone reporting a 4 is twice as satisfied as someone reporting a 2 . In this paper we adopt a cautious approach and assume cardinality. That is why, our baseline regressions are estimated by $\operatorname{OLS}^{21}$.

The estimate $\beta_{3}$ could hide the heterogeneous impact of decentralization dependent on

\footnotetext{
${ }^{18}$ Based on the 1979 National Classification of Occupations.

${ }^{19}$ Based on the two-digit National Classification of Economic Activities.

${ }^{20}$ According to fn. 3, this estimate could be a lower bound as long as a process of vertical yardstick competition raised the performance incentives of the central government.

${ }^{21}$ We have also run checks to determine whether imposing cardinality or ordinality changes the nature of the results (Ferrer-i-Carbonell and Frijters, 2004). In particular, we have estimated ordinary ordered logit model, and the qualitative results obtained via OLS still hold. These estimations are available upon request.
} 
population size. In terms of size, the ACs are quite heterogeneous; for example, the largest is Andalusia with a little more than 8 million inhabitants and the smallest is La Rioja, with a little more than 300,000 inhabitants. Hence, in Andalusia there are 25 inhabitants for every inhabitant of La Rioja. We expect the matching between individual preferences and public expenditure to be more accurate in the smallest ACs (see, for example, Dahlberg, Mörk and Ågren, 2005). For this reason, we amend the basic model as follows to account for differences in size:

$S_{i j t}=x_{i j t}^{\prime} \psi_{1}+a c_{j t}^{\prime} \psi_{2}+\psi_{3} D_{j t}+\psi_{4} D_{j t} \times P_{o p}+\psi_{5} P_{o p}+e_{i j t}^{\prime}$

In this specification, the $\psi_{s}$ pick up the corresponding estimates. We seek to ascertain the extent to which the impact of decentralization depends on population size. The estimate $\psi_{4}$ informs us about the marginal ability of decentralized governments to deal with large populations relative to the ability of the central government, which is picked up by $\psi_{5}$. Hence, for example, if $\psi_{3}>0$ and $\psi_{4}<0$, this would imply that the optimality of decentralized provision only holds up to a certain population threshold, while if $\psi_{4}=0$, this would imply that the gains or losses from decentralization are not size dependent. We will also allow for a more flexible specification of (2); in particular, we will test whether the impact of population interacted with decentralization is nonlinear.

The inclusion of control variables is critical for purposes of identification and for the interpretation of our estimates. First, in the above model, we control for fixed time effects. On the one hand, given the process of decentralization has evolved over time, it may coincide with global innovations in the process of public provision. On the other hand, due to electoral competition, the central government may have greater incentives to perform efficiently, which could cause a downward bias in the estimate of decentralization. In order to isolate the impact of decentralization from these potential biases, we include time effects in the above specification. Second, the inclusion of fixed effects (by AC) should control for structural differences in the needs or in the preferences that might bias our estimates ${ }^{22}$. Third, we aim to estimate gains in allocative

\footnotetext{
${ }^{22}$ Hence, the empirical strategy described so far controls both for time-invariant and timevarying unobservable characteristics, and also for important time-varying observable
} 
efficiency. In contrast with productive efficiency gains, this should imply a different composition of public expenditure, while keeping total public expenditure constant. For this reason we control for current public expenditure (Falch and Fischer, 2012), including it in the vector $a c_{j t}$. This might still be an imperfect control. However, our empirical analysis of satisfaction with (the administration of) justice administration where, if any, we should only obtain productive efficiency gains - should provide additional evidence about the nature of the potential gains of decentralization.

The basic specification (1) (or the amended model (2)) does not fully exploit all the institutional details of the Spanish case. The variable $D_{j t}$ in (1) accounts for all those situations in which the service has been decentralized to an AC independently of how the provision is funded. As discussed in previous sections, though, we can test whether the level of tax autonomy has an impact on the level of decentralized public good provision $^{23}$. For this reason we add to the basic specification (1) (and similarly to (2)) a dummy that picks up the higher level of tax decentralization since 1997. Specifically, we have the following:

$$
S_{i j t}=x_{i j t}^{\prime} \phi_{1}+a c_{j t}^{\prime} \phi_{2}+\phi_{3} D_{j t}+\phi_{4}\left(D_{j t} \times T D_{t}\right)+e_{i j t}
$$

According to the above specification, the base impact of provision decentralization is picked up by $\phi_{3}$. The variable $T D_{j}$ is a qualitative variable, which only shows time variation, as tax decentralization was introduced simultaneously across all ACs. The

heterogeneity such that we can reasonably be confident to produce causal estimates of decentralization. Nevertheless, simultaneity could still be an issue. As we argued in section 3, though, decentralization has not been a consequence of the (negative) assessment of public service provision, but was originally caused by the demand of self-government of some ACs (basically, Catalonia and the Basque Country), which in the end - by the mere pass of time and in order to avoid territorial tensions - made the rest of ACs also assumed those expenditure responsibilities.

${ }^{23}$ An interesting hypothesis to test based on the Spanish institutional context concerns the peculiarities of the "foral" communities described in section 3. Unfortunately, though, we cannot identify the impact of the "foral" communities having greater tax autonomy than the rest of the ACs, as we do not have a counterfactual, that is, introducing a dummy variable for them would confound with the AC fixed effect. 
ACs have enjoyed substantial tax powers since 1997 (Durán and Esteller-Moré, 2005) ${ }^{24}$. We expect $\phi_{4} \geq 0$.

Finally, note that the nature of the endogenous variable, which is based on a survey question, might cause a problem of representativeness. Indeed, the question might give rise to a potential misperception on the part of the respondent of the real public expenditure policy and a potential error in estimating the respondent's desired demand for public expenditure. On the one hand, errors regarding the perception of the real composition of public expenditure are presumably less likely among individuals that are better informed about the actions of the government. On the other hand, some individuals might tend to positively evaluate decentralized public policies regardless of the actual situation because of their nationalistic sentiments. We control for these variables (degree of information and self-identification as nationalistic) in levels and interact them with decentralization to account for these potential sources of bias.

\section{RESULTS}

\section{Basic Results}

All our estimates refer to marginal effects obtained by OLS estimations. The empirical results for education are shown in Table 4a. In Model 1, we present the basic model where we control for all individual characteristics and regional variables that might have an impact on the regional preferences and needs of public service provision, including time and regional fixed effects. To save space not all the estimates of individual characteristics are shown in the table, but they are available upon request. We discuss the estimated marginal effects - which account for the corresponding interactions -, but we also show in all tables the corresponding OLS estimates for these interaction terms. The absolute value of the estimated marginal effect of Decentralization on satisfaction with public provision of education is not statistically significant. However, in that model, we do not control for the level of total current

\footnotetext{
${ }^{24}$ In spite of the fact that tax decentralization occurred in 1997, it was not till 2001 when some ACs enacted important tax changes. We cannot identify, though, this particular impact as from 2001 all ACs had assumed Education and Health.
} 
expenditure pc, so the estimate might be a mix of productive (in)efficiency and allocative (in)efficiency. In an attempt at isolating this latter effect, in Model 2 we control for total current expenditure p.c. Then, the estimate of the marginal effect of Decentralization becomes slightly higher, but is still statistically insignificant ${ }^{25}$. In Model 3, we test whether the gains of decentralization depend on the population size of the region by means of interacting this variable with Decentralization. We have estimated marginal effects of Decentralization by population thresholds (not shown in the table) and the impact of decentralization is positive and statistically significant at $90 \%$ confidence level for those ACs of up to 2 million inhabitants, approximately. In Model 4, results do not change for the average $\mathrm{AC}$ when we account for the process of tax decentralization occurred since 1997, nor in Model 5 when we combine Model 3 and Model 4.

In Model 6, in part due to the statistical significance of the variable Population in levels in the previous regressions and to the heterogeneous estimated impact of Decentralization across population thresholds, we allow for a more flexible impact of population on our endogenous variable by means of including the variable Population non-linearly (i.e., Population and Population ${ }^{2}$ ), and also interacting Population and its squared with Decentralization ${ }^{26}$. This specification, which still controls for the potential impact of a greater level of tax autonomy since 1997, shows that decentralization has a positive impact $(0.227)$ for the average $\mathrm{AC}$ in terms of population size, being statistically significant at the $95 \%$ confidence level. This marginal effect corresponds to a $32.6 \%$ of the standard deviation of the level of satisfaction with the public provision of education. In Table $4 \mathrm{~b}$, we show the marginal effect estimated for different population thresholds. From these estimates, we infer greater levels of satisfaction due to decentralization concentrate on the smallest ACs; in particular, the welfare gains of decentralization are not statistically significant for regions with more than 1.8 million inhabitants, approximately ${ }^{27}$. For the largest ACs, certainly we also find a positive

\footnotetext{
${ }^{25}$ Note in absence of interactions, the marginal effect and the corresponding OLS estimate coincide.

${ }^{26}$ We thank the referee for suggesting to test for this possibility.

${ }^{27}$ This and the following population thresholds we estimate are not comparable with those much lower - found by Dahlberg, Mörk and Ågren (2005) (see section 2), as their study is conducted with local governments.
} 
impact, which is almost equal to the one obtained for the first considered threshold, but must be cautious about this given the estimates are not statistically significant within our population sample. The estimates are not statistically different between pre- and post-1997. The estimated impact of decentralization is relatively small, around a third of the standard deviation. At most, decentralization increases satisfaction by around 0.25 points (for the smallest regions), being 4 the highest value of this variable and 2.5 its average for the period under analysis (see Table 3). In terms of comparison with the rest of covariates, the magnitude of decentralization is the second largest. In fact, the magnitude of the effect is almost the same as the one from population, which is the largest one.

[TABLE $4 \mathrm{a} \& 4 \mathrm{~b}]$

The results for health provision are shown in Table 5a; its structure is identical to that of the previous table. The main difference in the empirical specifications for health is that - instead of the share of schooling population - we include the share of population over 65 years as a proxy for demand of health. The impact of decentralization is positive and statistically significant at the $90 \%$ confidence level in Model 2, that is, independently of the size of the AC. However, from Model 6, with respect to the results obtained for education, we obtain for health both a larger impact of decentralization and a higher degree of heterogeneity across population thresholds. This is shown by means of Table 5b. In particular, decentralization is welfare-enhancing for those ACs of up to 2.8 millions inhabitants, approximately, there being an increasing trend till a maximum at the range of 1.8-2.8 millions inhabitants. However, nothing can be said above this threshold, again, for inefficiency of our estimates from this point of the distribution onwards. The impact of the greater level of tax autonomy since 1997 goes in the contrary direction - towards a lower level of satisfaction -, being the difference between the estimates pre- and post-1997 statistically significant at the $90 \%$ confidence level. At most (for the period pre-1997 and for medium-size regions), the impact of health decentralization on satisfaction is around 0.6 points, being the average of the period equal to 2.4 (see Table 3). That is, the favorable impact of decentralizing health provision is almost three times the positive impact of decentralizing education. In particular, this marginal effect accounts for $73.6 \%$ of the standard deviation of the level of satisfaction with public provision of health. Also, comparatively to the rest of 
covariates, the effect from decentralization is the largest one.

\section{[TABLE 5a \& 5b]}

In Table 6a, we present the whole set of results for justice; and in Table $6 \mathrm{~b}$ by population thresholds. In this case, we do not have a proper variable to account for demand, although we presume GDP pc, Population or the time and regional fixed effects play this role. Expenditure decentralization is not welfare enhancing independently of whether tax revenue is also decentralized or of the level of regional population. This is not unexpected, since as we said in section 3 the nature of expenditure decentralization is merely administrative. Moreover, the average respondent to the survey might not be a (current or past) user of the service, and so might assess public provision based on a consideration of justice as a pure public good rather than as a private service. This might be why population does not have any impact on the private assessment of public service provision. Still those that are better informed express a more negative assessment of public provision. Finally, in contrast with the other two public services, where the estimate was not statistically significant, those individuals identified as nationalistic systematically express a negative view of the service. Again, this is further evidence that they are implicitly assessing a pure public service, which is provided all over Spain, and that they may well link it to the concentration of power in central government and so the situation does not change when the administration is decentralized.

[TABLE 6a \& 6b]

All in all, we find decentralization to be welfare enhancing in those cases where this not only implies that regional governments administer the service, but they also have a certain political power. However, the benefits of decentralization crucially depend on the population size of the region ${ }^{28}$, while we do not find empirical evidence in favor of a

\footnotetext{
${ }^{28}$ In order to have as a reference, in the period 1994-2011, La Rioja, Cantabria, Navarre, Balearic Islands, Extremadura, Asturias, Aragón and Murcia had less than 1.8 million inhabitants. Canary Islands, Castile-La Mancha, the Basque Country, Castile- León and Galicia had between 1.8-2.8 million inhabitants.
} 
positive impact of tax revenue decentralization ${ }^{29}$. Note our results are in accordance with those obtained by Díaz-Serrano and Rodríguez-Pose (2015) in favor of the efficiency gains due to the decentralization of education and health, in their case, using a cross-country sample of European countries.

\section{Robustness Checks}

In this section, we present robustness checks for all three areas of expenditure. The results for education, health and justice are shown in Table 7. Remember we display marginal effects. The structure of each set of estimations is the same, while the individual and regional controls in each case are the same as those used when obtaining our previous results.

The responses obtained in the survey might be biased, given that some individuals may not be real users, while some users might per se tend to be less critical with the decentralized provision, for example, those who define themselves as nationalistic. For this reason, in the rest of the models presented in the tables, we not only include the variable Level of information and Nationalistic in levels, but we also interact them with Decentralization. From the results, we infer that accounting for these potential biases does not make our previous average marginal effects (not distinguishing between pre and post-1997) vary.

[TABLE 5a \& 5b]

\section{CONCLUSIONS}

The trend recorded the world over in favor of expenditure decentralization is coherent with the welfare gains identified by Tiebout (1956) and Oates (1972) attributable to allocative efficiency. In particular, this literature concludes that - in the absence of economies of scale (a production-side argument) and inter-jurisdictional externalities -

\footnotetext{
${ }^{29}$ Once could certainly argue that this is due to an imperfect or incomplete tax revenue decentralization process (see, for example, Lago-Peñas and Martínez-Vázquez, 2010).
} 
decentralized provision is at least as efficient as centralized provision. Most of the empirical literature reviewed in section 2 supports this argument. In this paper, we have tested this claim using survey data, and have sought to infer whether the welfare gains attributable to expenditure decentralization - if any - are present for all regions independently of their size and whether there is any further gain associated with tax revenue decentralization.

We have tested the claim for three key services: education, health and justice. In the Spanish case, though, political decentralization only really holds for the first two services. Logically, therefore, we only obtain welfare gains for education and health, as we were only able to estimate allocative efficiency gains with respect to these two services. However, we need to be cautious, since the specific gains attributable to decentralization are not statistically significant for all regions; in particular, results are not conclusive for regions with more than 1.8 million inhabitants (accounting for 9 out of 17 regions), or for those with more than 2.8 million in the case of health (accounting for 4 out of 17 regions). This basic result is independent of the process of tax revenue decentralization initiated in 1997 (see also fn. 29). Given these results, it seems that the advantages of expenditure decentralization with respect to centralization should not be taken for granted. Empirical studies of other public services should shed further light on this important issue, especially focused on large jurisdictions where the benefits from decentralization are not well estimated.

\section{REFERENCES}

Arze del Granado, F. Javier, Jorge Martínez-Vazquez, Robert M. McNab (2012). Decentralized Governance and Preferences for Public Goods, MPRA Paper 42459, University Library of Munich, Munich, Germany.

Balaguer-Coll, Maria Teresa, Diego Prior, Emili Tortosa-Ausina (2010). Decentralization and efficiency of local government, Annals of Regional Science. 45: 571-601.

Bardhan, Pranab K., Dilip Mookherjee (2000). Capture and Governance at Local and National Levels, American Economic Review. 90: 135-139.

Barankay, Iwan, Ben Lockwood (2007). Decentralization and the productive efficiency of government: Evidence from Swiss cantons, Journal of Public Economics. 91: 11971218. 
Besley, Timothy J., Anne Case (1995). Incumbent Behavior: Vote-Seeking, Tax Setting, and Yardstick Competition, American Economic Review. 85: 25-45.

Besley, Timothy J., Stephen Coate (2003). Centralized Versus Decentralized Provision of Local Public Goods: A Political Economy Approach, Journal of Public Economics. 87: 2611-2637.

Bjørnskov, Christian, Axel Drehe, Justina A.V. Fischer (2008). On decentralization and life satisfaction, Economics Letters. 99: 147-151.

Bordignon, Massimo, Luca Colombo, Umberto Galmarini (2008). Fiscal Federalism and Lobbying, Journal of Public Economics. 92: 2288-2301.

Borge, Lars-Erik, Jan K. Brueckner, Jorn Rattsø (2014). Partial Fiscal Decentralization and Demand Responsiveness: Theory and Evidence from Norway, Journal of Urban Economics. 80: 153-163.

Breton, Albert, Angela Fraschini (2003). Vertical competition in unitary states: The case of Italy, Public Choice. 114: 57-77.

Brueckner, Jan K. (2009). Partial fiscal decentralization, Regional Science and Urban Economics. 39: 23-32.

Caldeira, Emilie, Martial Foucault, Grégoire Rota-Graziosi (2012). Does Decentralization Facilitate Access to Poverty-Related Services?: Evidence from Benin, NBER Working Paper \#18118, National Bureau of Economic Research, Cambridge, Massachusetts.

Calero, Jorge, Josep-O. Escardíbul (2005). Financiación y desigualdades en el sistema educativo y de formación profesional de España, in: Navarro, V. (ed.), La situación social de España. Madrid: Biblioteca Nueva- Fundación Largo Caballero: 337-384.

Cantarero, David, Marta Pascual (2008). Analysing the impact of fiscal decentralization on health outcomes: empirical evidence from Spain, Applied Economics Letters. 15: 109-111.

Clark, Andrew E., Paul Frijters, Michael A. Shields (2008). Relative income, happiness, and utility: An explanation for the Easterlin paradox and other puzzles, Journal of Economic Literature. 46: 95-144.

Dahlberg, Matz, Eva Mörk, Hanna Ågren (2005). On the Size of Political Jurisdictions: An Examination of Preference Matching. Paper presented at the I IEB Workshop on Fiscal Federalism.

Diaz-Serrano, Luis, Andrés Rodríguez-Pose (2012). Decentralization, Happiness and the Perception of Institutions, Kyklos. 65: 179-193.

Diaz-Serrano, Luis, Andrés Rodríguez-Pose (2015). Decentralization and the Welfare State: What Do Citizens Perceive, Happiness and the Perception of Institutions, Social 
Indicators Research. 120: 411-435.

Durán, José $\mathrm{M}^{\mathrm{a}}$, Alejandro Esteller-Moré (2005). Descentralización fiscal y política tributaria de las CCAA. Un primera evaluación a través de los tipos impositivos efectivos en el IRPF, in: Núria Bosch and José $\mathrm{M}^{\mathrm{a}}$ Durán, La financiación de las comunidades autónomas: políticas tributarias y solidaridad interterritorial. Barcelona: Editorial Universitat de Barcelona (Transformacions 1.1): 47-86.

Eichenberger, Reiner (1994). The Benefits of Federalism and the Risk of Overcentralization, Kyklos. 47: 403-420.

Eppel, Dennis, Thomas Nechyba (2004). Fiscal Decentralization, in: J. Vernon Henderson and Jacques-François Thisse, Handbook of Regional and Urban Economics, Vol. 4, Amsterdam: Elsevier: 2423-2480.

Esteller-Moré, Alejandro, Albert Solé-Ollé (2005). "Does decentralization improve the efficiency in the allocation of public investment? Evidence from Spain", Working Paper of the IEB \#5, Barcelona, Spain.

Esteller-Moré, Alejandro (2013). Trust in the Justice Administration: Is it Dependent on the Economic Cycle and on Decentralization?, Environment \& Planning C: Government \& Policy. 31: 505-521.

Faguet, Jean-Paul (2004). Does Decentralization Increase Government Responsiveness to Local Needs?: Evidence from Bolivia, Journal of Public Economics. 88: 867-893.

Falch, Torberg, Justina A.V. Fischer (2012). Public sector decentralization and school performance: International evidence, Economics Letters. 114: 276-279.

Ferrer-i-Carbonell, Ada and Paul Frijters (2004). How important is methodology for the estimates of the determinants of happiness?, The Economic Journal. 114: 641-659.

González-Alegre, Juan (2010). Decentralization and the Composition of Public Expenditure in Spain, Regional Studies. 44: 1067-1083.

Goodspeed, Timothy J. (1994). Efficiency and Equity Consequences of Decentralized Government: An Application to Spain, International Tax and Public Finance. 1: 35-54.

Hoxby, Caroline M. (2000). Does Competition Among Public Schools Benefit Students and Taxpayers, American Economic Review. 90: 1209-1238.

Kyriacou, Andreas P., Oriol Roca-Sagalés (2011). Fiscal and political decentralization and government quality, Environment and Planning C: Government and Policy. 29: 204-223.

Lago-Peñas, Santiago, Jorge Martínez-Vázquez (2010). La descentralización tributaria en las comunidades autónomas de régimen común: un proceso inacabado, Hacienda Pública Española/Review of Public Economics. 192: 129-151.

Litvak, Jennie, Junaid Ahmad, Richard Bird (1998). "Rethinking Decentralization in 
Developing Countries", The World Bank Sector Studies Series, World Bank, Washington D.C.

Mora, Toni, Josep-O. Escardíbul, Marta Espasa (2010). The effects of regional educational policies on school failure rates in Spain, Revista de Economía Aplicada. 54: 79-106.

Oates, Wallace E. (1972). Fiscal Federalism. New York: Harcourt Brace Jovanovich.

Oates, Wallace E. (2005). Toward a second-generation theory of fiscal federalism, International Tax and Public Finance. 12: 349-373.

Peralta, Susana (2011). Partial fiscal decentralization, local elections, and accountability, mimeo.

Prud'homme, Rémy (1995). The dangers of decentralization, World Bank Research Observer. 10: 201-220.

Rodríguez-Pose, Andrés, Nicholas Gill (2005). On the 'Economic Dividend' of Devolution, Regional Studies. 39: 405-420.

Seabright, Paul (1996). Accountability and decentralisation in government: An incomplete contracts model, European Economic Review. 40: 61-89.

Solé-Vilanova, Joaquim (1989). Spain: Development in Regional and Local government, in: Robert J. Bennett (ed.), Territory and Administration in Europe. London: 205-229.

Tiebout, Charles M. (1956). A pure theory of local expenditures, Journal of Political Economy. 64: 416-424.

Treisman, Daniel (2002). Decentralization and the quality of government, mimeo.

Weingast, Barry R. (1995). "The Economic Role of Political Institutions: MarketPreserving Federalism and Economic Development", The Journal of Law, Economics and Organization. 20: 1-31.

Weingast, Barry R. (2009). Second generation fiscal federalism: The implications of fiscal incentives, Journal of Urban Economics. 65: 279-293.

Wildasin, David E. (1995). Comments on 'Fiscal Federalism and Decentralization: A Review of Some Efficiency and Macroeconomic Aspects' by Vito Tanzi. Paper prepared for the Annual Bank Conference on Development Economics, May 1-2, 1995, The World Bank, Washington DC. 
Figure 1. Evolution of the Spanish Decentralization Process (1970-2011)
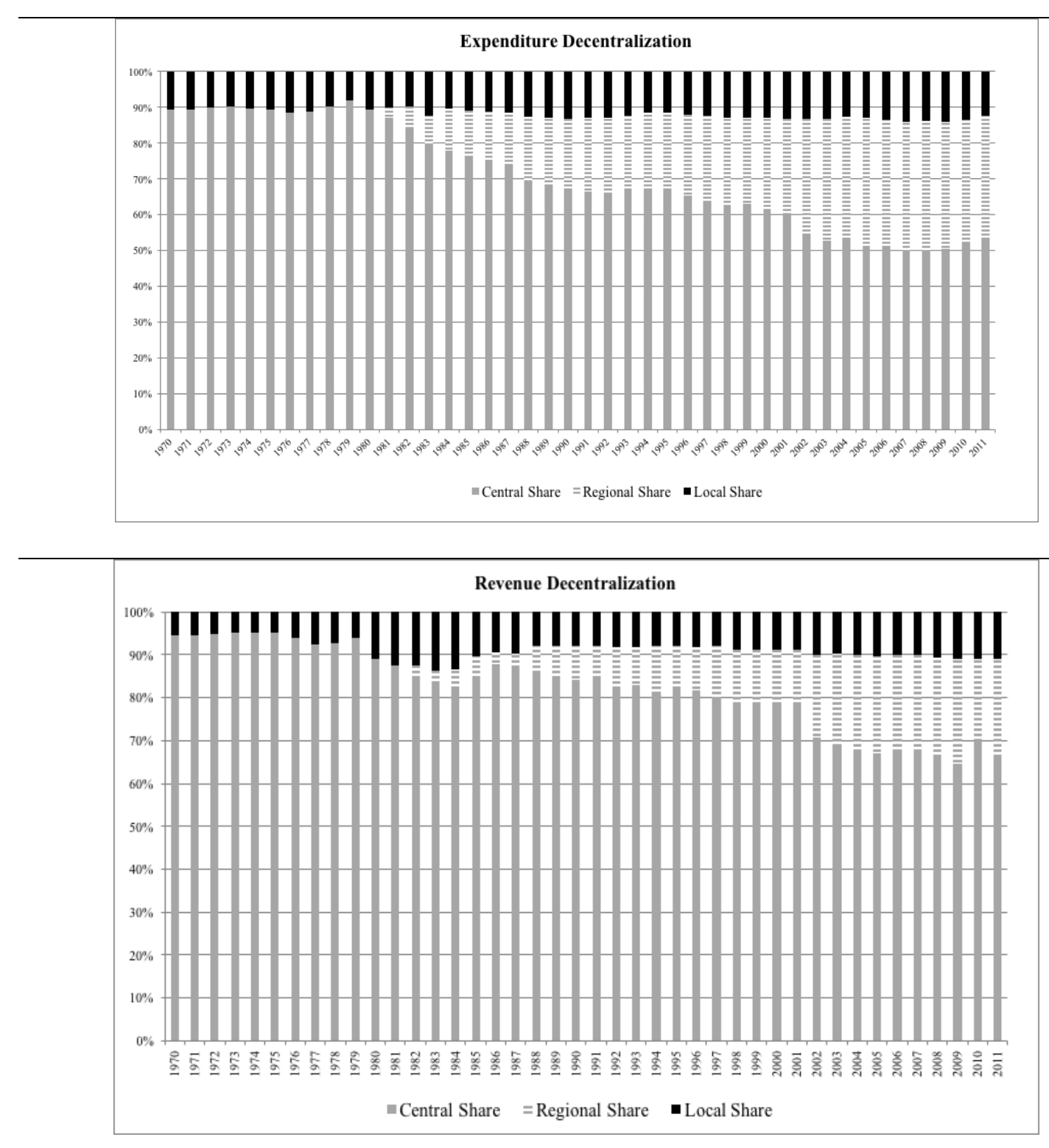

Sources: 1980-83: Bosch, N., J. Suárez-Pandiello, M. Espasa (1996): Local public finance in Europe: The case of Spain, European Commission. 1984-98: DG de Coordinación con las Haciendas Territoriales: La descentralización del gasto público en España. 1999-2001: Ministerio de Administraciones Públicas: Informe Económico-Financiero de las Administraciones Territoriales. 2002-2011: IGAE: Avance de la Actuación Presupuestaria de las Administraciones Públicas. 